\title{
BIBLIOTECA UNIVERSITÁRIA E SABERES INFORMACIONAIS: UMA EXPERIÊNCIA COM A WIKIPÉDIA
}

\author{
UNIVERSITY LIBRARY AND THE PROCESS OF \\ DEVELOPING NEW INFORMATIONAL KNOWLEDGE: AN \\ EXPERIENCE WITH WIKIPEDIA
}

\author{
Lilian Viana ${ }^{1}$ \\ Ivete Pieruccini² \\ Stela Nascimento Madruga ${ }^{3}$
}

\begin{abstract}
RESUMO
Objetivo: A partir de experiência realizada de modo articulado entre biblioteca universitária e sala de aula, com o emprego da enciclopédia digital Wikipédia, o estudo aborda a biblioteca universitária como dispositivo educativo, ocupado com a apropriação de saberes informacionais pelos estudantes. Metodologia: Pesquisa qualitativa, exploratória e participante. Resultados: A experiência revelou indícios do potencial de uso da Wikipédia em práticas de produção textual que contribuam à construção, junto aos estudantes, de percepções acerca da apropriação e da produção de informações na cultura científico-acadêmica. Além disso, expôs a relevância da biblioteca universitária como dispositivo educativo ao se ocupar com ações voltadas às dinâmicas de produção de sentidos no contexto científicoacadêmico. Conclusões: $O$ estudo destacou a importância dos diálogos entre biblioteca universitária e sala de aula por meio do desenvolvimento de ações que tenham como uma meta comum, a ambas as esferas, a formação do estudante como sujeito que se relaciona afirmativamente com informação e conhecimento. Considerouse que, ao desenvolvimento da dimensão educativa da biblioteca universitária, são demandadas metodologias e práticas concretas em torno da apropriação de saberes informacionais, aspecto que levou a pontuar o potencial de uso da Wikipédia em ações relacionadas aos processos de pesquisa, leitura, escrita e, também, para o estudante experimentar a escrita como ato autônomo e criativo.
\end{abstract}

1 Doutora em Ciência da Informação pela Universidade de São Paulo (USP). E-mail: lilianviana@usp.br

2 Doutora em Ciências da Comunicação pela Universidade de São Paulo (USP). Docente da Escola de Comunicações e Artes da Universidade de São Paulo (USP). E-mail: ivetepie@usp.br

3 Mestre em Gestão da Informação pela Universidade de São Paulo (USP). E-mail: stela.madruga@usp.br 
Descritores: Biblioteca universitária. Educação superior. Saberes informacionais. Wikipédia.

\section{INTRODUÇÃO}

A biblioteca universitária caracteriza-se como dispositivo privilegiado de reunião, organização e disponibilização de produção científica, técnica e artística em seus respectivos âmbitos de atuação, desempenhando função informativa específica, em atendimento à comunidade acadêmica. Nessa ação essencial, atua como instância de preservação e difusão de conhecimentos, práticas intrinsecamente ligadas aos fundamentos que definem sua existência na esfera universitária. Tal perspectiva, contudo, observa somente um aspecto - a função informativa - da biblioteca universitária, questão que merece ser problematizada, considerando-se tanto a ordem informacional contemporânea, com suas novas dinâmicas, códigos e práticas, quanto os contextos socioculturais (sobretudo brasileiros) nos quais este organismo se inscreve.

De fato, considerando-se observações levadas a efeito em pesquisa recente (VIANA, 2021), evidencia-se que o papel da biblioteca universitária na educação superior restringe-se, frequentemente, à oferta informacional. $O$ acesso às fontes de informações é marca constante das narrativas sobre a biblioteca universitária, condição que a coloca como instância acessória do processo educativo, a ser exercido quase que exclusivamente pela sala de aula. Nesses termos, a educação na chamada "era da informação" (MATTELART, 2002) salienta contradição séria na medida em que, diante dos grandes volumes informacionais que marcam a atualidade, uma das possíveis contribuições da biblioteca universitária seria propiciar experiências significativas com a diversidade informacional e cultural, essencial aos processos de formação do estudante como alguém que se relaciona de modo crítico, rigoroso e criativo com informações e conhecimentos.

A questão acentua cada vez mais a importância da apropriação de saberes informacionais, categoria estruturante das dinâmicas intelectuais e afetivas implicadas no processo de transformação da matéria simbólica em 
algo próprio, ou seja, de apropriação cultural (CHARTIER, 1999; PERROTTI; PIERUCCINI, 2013).

Este enfoque, porém, representa mudança de paradigma, envolvendo novos modelos de atuação da biblioteca universitária, suas ações e metodologias concretas, bem como práticas de trabalho voltadas a incluir circuitos estudantis em processos de produção de conhecimento e comunicação escrita em meio eletrônico, tendo em vista públicos diversificados.

O presente texto sintetiza experiência voltada a questionar acerca desses aspectos e dos desafios que colocam à práxis, partindo-se de proposta realizada de modo articulado entre biblioteca universitária e sala de aula, tendo como base a redação, por estudantes universitários, de verbetes na Wikipédia, enciclopédia digital pautada em ideais de abertura e compartilhamento.

A ação ocorreu em 2020, a partir da atuação conjunta entre duas bibliotecárias - vinculadas às bibliotecas da Escola de Comunicações e Artes (ECA) e do Instituto de Matemática e Estatística (IME), ambos da Universidade de São Paulo (USP) - e a docente, responsável pela disciplina de graduação "Infoeducação: teoria e prática", oferecida no curso de Biblioteconomia do Departamento de Informação e Cultura (CBD) da ECA-USP.

A iniciativa buscou, de um lado, introduzir os estudantes em dinâmicas de compreensão da informação como construção social (LOGAN, 2012), noção objetivada e significada concretamente por meio de processos que incluem a busca informacional, a leitura de textos diversificados e a escrita autoral; de outro, a atividade visou contribuir com a construção de percepções acerca da responsabilidade social na comunicação de conteúdos informacionais. Assim, a ação foi pautada na possibilidade de os participantes experimentarem a si mesmos como produtores de informações de caráter público e coletivo.

Nesse sentido, a Wikipédia configurou objeto privilegiado às nossas incursões, pois é enciclopédia digital colaborativa, de amplo alcance - entre janeiro e dezembro de 2020, o conteúdo em português foi alvo de mais de 4,2 bilhões de visualizações, sendo um dos sites mais acessados no Brasil neste período -, com conteúdo livre que pode ser editado a qualquer momento, por 
qualquer pessoa, desde que respeitados certos princípios que delineiam esse ambiente de produção e partilha informacional (WIKI MOVIMENTO BRASIL, 2020).

\section{APRENDIZAGENS INFORMACIONAIS NA EDUCAÇÃO SUPERIOR: O ENFOQUE DA BIBLIOTECA UNIVERSITÁRIA}

As relações que estabelecemos com o universo simbólico delimitam formas de ser, estar e conhecer o mundo. Por esta razão, a apropriação cultural (CHARTIER, 1999) é questão que impacta a vida, tratando-se de processo que demanda mais que acesso a informações, mais que o simples encontro entre sujeitos e signos. Embora fundamental, o oferecimento de produtos da cultura escrita, por si só, não constitui medida que garanta relações afirmativas entre sujeitos e o universo do conhecimento.

Nesse sentido, a problemática da construção de vínculos com o patrimônio simbólico no contexto da educação brasileira - aí incluída a educação superior - refere-se aos graves aspectos que aprofundam a manutenção de distâncias culturais entre sociedade e conhecimento. Tal aspecto reforça a importância de práticas de aprendizagem informacional em contextos educativos, dentre estes, a educação superior, também marcada por fraturas culturais que afetam a relação do estudante universitário com informações científicas e conhecimentos acadêmicos.

Conforme apontam estudos (COULON, 2008; BELLETATI, 2011; ADACHI, 2017; VIANA, 2021), dentre o rol de dificuldades vivenciadas pelos estudantes destacam-se processos relativos à pesquisa, leitura e escrita acadêmica, indicativos de problemas ligados à questão informacional e que são centrais à formação superior. $\mathrm{O}$ ato da pesquisa, que inclui saber buscar $\mathrm{e}$ avaliar informações, implica autonomia e discernimento, requerendo criticidade e rigor, sobretudo face aos grandes volumes informacionais que marcam a atualidade. Muito além do domínio de ferramentas, pesquisar compreende condutas, procedimentos e processos singulares à relação com as informações e seus circuitos de produção e comunicação; é ato inscrito em esfera que 
pressupõe a curiosidade epistemológica (FREITAS, 2008) e compreende a mobilização do sujeito (CHARLOT, 2008), implicando suas experiências e o desejo de conhecer.

De outro lado, desenvolver uma ideia em linguagem escrita, demonstrando, citando e elaborando referências adequadamente é desafio para muitos estudantes, inscrito na própria incompreensão do sentido e valor de determinadas regras discursivas e de elaboração textual (BELLETATI, 2011). Para Becker (2015) é recorrente que o próprio estudante não construa a imagem de si como um potencial autor, em decorrência das deficiências de práticas de escrita em seu trajeto educacional, aspecto que dificulta sua participação efetiva na ordem simbólica como sujeito de palavra (CAUNE, 2000), que se comunica por meio da produção textual.

Assim, esses elementos atestam que a produção de informações e conhecimento na educação superior compreende muito mais que o binômio oferta-acesso aos repertórios sígnicos, inscrevendo a problemática no âmbito da biblioteca universitária, instância capaz de atuar na construção de relações críticas e afirmativas entre estudantes, informações e conhecimentos e de abrir espaço, portanto, à atitude protagonista em relação aos signos, fundamental na esfera acadêmica. No âmbito da biblioteca universitária, práticas que propiciem aos estudantes universitários experiências com 0 universo informacional merecem, portanto, ser consideradas e estudadas, dadas as condições e objetivos singulares que as distinguem de dinâmicas próprias de sala de aula.

Dois aspectos são relevantes nessa distinção: o primeiro diz respeito ao uso potencial do patrimônio infodocumental (VIANA, 2021) da biblioteca universitária; o outro, refere-se ao foco sobre os saberes informacionais, termo empregado para definir meta-conhecimentos, ou seja, conhecimentos sobre o próprio conhecimento, constituindo elementos que favorecem a reflexão acerca de sua natureza, lógicas e processos. Tais saberes, de caráter transversal, diferem dos conteúdos conceituais ou procedimentais das distintas áreas de conhecimento configurando-se, entretanto, como essenciais à apropriação desses conteúdos. Resultam de processos de aprendizagens e de experiências informacionais e culturais em contextos concretos, tais como as bibliotecas 
universitárias, que criem condições para que os sujeitos experimentem relações críticas e criativas com o universo simbólico, podendo reelaborar a si mesmos e ao próprio mundo nesse processo (PERROTTI; PIERUCCINI, 2013).

Os saberes informacionais caracterizam-se, nessa dimensão, como meta-conhecimentos que atuam como possibilidades à qualificação e significação do processo de produção de informações, no qual a biblioteca universitária ocupa posição privilegiada. Nesse sentido, a biblioteca tem o poder de extrapolar perspectivas de desenvolvimento de competências para utilizar ferramentas e manipular documentos, as aptidões técnicas são redutoras quando estão em causa os atos de sujeitos que atribuem sentido ao que são e àquilo que thes acontece a partir de suas experiências e repertórios (BRUNER, 1990; PIERUCCINI, 2004; PERROTTI, 2009, LARROSA 2015).

Este trabalho enfatiza, portanto, que abordagens pautadas no diálogo entre biblioteca e sala de aula assumem posição de destaque na medida em que poderiam facilitar a articulação entre saberes da Informação e da Educação, tendo como meta comum a formação do estudante como alguém que se relaciona afirmativamente com repertórios simbólicos, socializando-os em processos de pesquisa, leitura e escrita acadêmica. Tais aspectos foram propulsores da experiência objeto deste relato, envolvendo biblioteca universitária e sala de aula, em práticas de aprendizagem informacional com o uso da Wikipédia.

\section{A WIKIPÉDIA: UM INSTRUMENTO PARA A AÇÃO}

Fundada em 2001 por Jimmy Wales e Larry Sanger, a Wikipédia está disponível em diferentes idiomas e possui mais de um milhão de artigos em português (WIKI MOVIMENTO BRASIL, 2020). Essa enciclopédia digital livre e gratuita opera a partir de um modelo que Burke (2012) define como "de baixo para cima", com conteúdos produzidos pela própria comunidade de uso, composta por amadores ou, ainda conforme o autor, por estudiosos diletantes, desejosos em contribuir com a produção de informações de qualidade sobre determinado tema. 
Pautada em parâmetros da produção enciclopédica, a Wikipédia não tem por princípio a produção de novos conhecimentos, mas, apresentar uma síntese daqueles já existentes, contemplando a exposição de diferentes abordagens sobre um mesmo tema. Nessa direção, a produção enciclopédica contribui ao desenvolvimento dos conhecimentos nas sociedades, ao construir consensos sobre determinados assuntos (VANDERDORPE, 2015). Mais que repositórios de conteúdos intelectuais, enciclopédias organizam 0 conhecimento, assim, contribuem para reflexões em torno da própria noção de informação e conhecimento como produção social, compreendendo suas naturezas e processos de validação, outro aspecto a ser considerado pela biblioteca universitária no desenvolvimento de ações com a comunidade acadêmica.

Empregar a Wikipédia em práticas de pesquisa e escrita poderia contribuir para construir, junto aos estudantes, compreensões em torno das noções e processos de informação e conhecimento, por meio de dinâmicas de diálogo com o universo informacional que impliquem argumentação e exposição de ideias de forma coerente, pautadas em argumentos consistentes e referenciados. Nessa perspectiva, redigir textos numa enciclopédia digital expõe seus colaboradores aos desafios da apropriação da escrita acadêmica como ato que submete a posição valorativa e o juízo de valor à argumentação rigorosa e metódica.

A dimensão colaborativa presente na Wikipédia é outro aspecto que a torna relevante ao desenvolvimento de práticas em torno da informação. Além da redação de um mesmo texto por diferentes pessoas, essa característica está presente em recursos como a página de discussão que possibilita, em caso de desacordo sobre determinado texto, que os autores dialoguem em busca de consenso, de forma pública e registrada, permitindo que todos acompanhem a evolução do verbete (VANDERDORPE, 2015). Reverter edições, visualizar o histórico da redação dos verbetes, monitorar edições dos autores e políticas de eliminação de novos verbetes são elementos que fazem da Wikipédia um dispositivo propício à compreensão de que a informação não é neutra e, sobretudo, legitima que é bem simbólico e implica partilha. Tal 
aspecto contribui ao desenvolvimento de abordagens em torno da importância de uma escrita fundamentada em referenciais consistentes que sejam adequadamente explicitados ao leitor do texto.

A Wikipédia também possui certa dimensão crítica, evidenciada em alertas presentes nos artigos, como os que seguem: dado trecho do texto carece de fontes; um artigo cita fontes confiáveis, mas não cobrem todo 0 conteúdo; a confiabilidade de um artigo está comprometida pois as fontes referenciadas não são citadas junto ao conteúdo; um artigo é um esboço que demanda melhorias; um texto está escrito a partir de um viés geográfico que pode comprometer uma compreensão mais ampla do tema.

Esses indicativos, se tomados como críticas ao teor e formatação do texto, constituem recursos que podem ser explorados em práticas de aprendizagem informacional que favoreçam o desenvolvimento do estudante enquanto leitor e autor. De um lado, os alertas contribuem na construção de parâmetros para avaliar a informação, ultrapassando as fronteiras da Wikipédia; de outro, para que a produção textual apresentada não dispense 0 rigor, chamando a atenção para o fato de que tais elementos são analisados e criticados pelos leitores e que, portanto, exigem ser observados no momento da elaboração do texto.

Nesses termos, vale destacar que a Wikipédia é frequentemente descreditada como fonte de informação confiável, dada sua característica livre e editável por todos. Muitos professores afirmam aos estudantes que não é adequado citar a Wikipédia em seus trabalhos escolares, contudo, tal afirmação por si só, ou pautada exclusivamente em argumentos que problematizam a escrita colaborativa por amadores não identificados, não contribui para que o estudante desenvolva parâmetros para avaliar informações de forma mais ampla.

Práticas que comportem usos da Wikipédia podem contribuir para que 0 estudante desenvolva compreensões acerca da identificação de fontes confiáveis que pautam o texto, de como realizar uma leitura crítica, superando entendimentos que resumem o valor da informação ao critério de autoridade (VANDERDORPE, 2015; WIKI MOVIMENTO BRASIL, 2020). Se a Wikipédia 
pode apresentar erros e a confiabilidade de certos conteúdos é questionável, o mesmo pode ocorrer com informações produzidas e comunicadas em diferentes contextos, incluindo o acadêmico. $O$ que difere é a procedência das informações, seus referenciais de validação e de fidedignidade havendo, nesse sentido, distinções significativas. Todavia, o que impacta o leitor-autor é a esfera atitudinal, categoria mobilizadora da busca por informações e conhecimentos consistentes e procedentes, em todo e qualquer contexto.

Ao desenvolver atividades pedagógicas com o emprego da Wikipédia, as Instituições de Ensino Superior (IES) podem contribuir com a garantia do direito de acesso a informações de boa qualidade sobre temas diversos que perpassam o contexto científico-acadêmico. Por meio de ações junto aos estudantes, que resultam na produção de verbetes de fácil compreensão ao público em geral, as IES contribuem para a circulação de conteúdos produzidos na academia, pois na Wikipédia está em causa a produção de textos enciclopédicos e generalistas, redigidos em linguagem acessível a nãoespecialistas.

Dentre diversos estudos sobre o emprego da Wikipédia em práticas educativas, destacamos pesquisa realizada por Meseguer-Artola et al. (2020) com 2.330 estudantes de uma universidade europeia. Os autores sugerem que práticas com a Wikipédia - articulada a outros recursos de informação em suportes variados -, podem contribuir para que os estudantes compreendam diferentes aspectos implicados na informação, que pode variar conforme contextos de produção e comunicação, assim como devido ao seu suporte.

No contexto brasileiro, Brescia et al. (2015) discutem as potencialidades da Wikipédia na educação superior, ao ser empregada em práticas de leitura, escrita e comunicação no contexto digital. Tomada como plataforma que articula possibilidades para o estudante experimentar a si mesmo como leitor e autor, os pesquisadores argumentam que a Wikipédia tem potencial para contribuir no desenvolvimento de práticas educativas que visam o estudante como produtor de sentidos, retirando-o da posição de quem somente assimila conteúdos transmitidos pelo professor. 
Thomas, Jones e Mattingly (2021), apresentam projeto desenvolvido de modo articulado entre o Departamento de Biologia e as bibliotecas da Universidade de Kansas (KU), nos Estados Unidos. Na iniciativa em causa, a Wikipédia foi empregada como recurso para o desenvolvimento de práticas de ensino-aprendizagem sobre o processo de revisão por pares de textos científicos. Os estudantes redigiam e revisavam textos de modo colaborativo, o que contribuiu para que se apropriassem de dinâmicas do processo editorial de revistas científicas e, além disso, para estimular reflexões sobre o movimento de acesso aberto ao conhecimento, como também sobre a importância de iniciativas de divulgação científica.

Tais estudos, que ressaltam possibilidades de uso da Wikipédia em práticas pedagógicas centradas na relação do estudante com informação e conhecimento no contexto digital, evidenciam a centralidade da questão informacional na formação superior. Como recurso ao desenvolvimento de práticas educativas, a Wikipédia apresenta possibilidades a serem exploradas em termos de pesquisa, leitura, produção textual, análise de conteúdos, produção colaborativa, argumentação em defesa de uma ideia, entre outros aspectos.

De um lado, esses elementos indicam a importância de ações concretas em torno do desenvolvimento de uma relação crítica, criativa e rigorosa entre estudantes, informação e conhecimento, de outro, apontam para um espaço a ser ocupado pela biblioteca universitária, ao evidenciarem que na formação do estudante não está em causa somente o acesso às informações, mas a apropriação simbólica, tornar-se autor, um produtor de sentidos no contexto acadêmico.

A questão salienta a importância do desenvolvimento de outros modelos de atuação da biblioteca universitária e a pertinência de se investigar a Wikipédia como recurso para proposição de ações e metodologias concretas em torno dos processos de apropriação de informações e produção de conhecimentos pelos estudantes universitários. 


\section{BIBLIOTECA UNIVERSITÁRIA EM PRÁTICAS DE APRENDIZAGEM INFORMACIONAL: UMA EXPERIÊNCIA COM A WIKIPÉDIA}

A ação objeto do relato foi desenvolvida no contexto do projeto GLAMWiki das Bibliotecas da USP 4 iniciativa que surge em junho de 2020 incluindo as bibliotecas da ECA-USP, IME-USP e Faculdade de Arquitetura e Urbanismo (FAU) da USP, com o objetivo de desenvolver práticas com ferramentas e projetos Wikimedia - movimento global que tem como missão compartilhar conteúdo livre ao redor do mundo - dentre estes, a Wikipédia. Com isso, o GLAM-Wiki das Bibliotecas da USP visa contribuir com processos de organização e disponibilização de informações em acesso aberto, bem como com o desenvolvimento de ações em torno da relação do estudante com informações científicas.

$\mathrm{Na}$ experiência em foco neste estudo os estudantes da disciplina Infoeducação: teoria e prática (períodos matutino e noturno), oferecida idealmente no $2^{-}$semestre do curso de graduação em Biblioteconomia da ECA-USP, foram convidados a desenvolver, como trabalho final da disciplina, um verbete na Wikipédia em português. A ação, planejada e implementada em meio à pandemia da COVID-19, foi realizada no $2^{-}$semestre de 2020 no formato online.

\subsection{Diálogos Biblioteca Universitária e Sala de Aula: Papéis e Dinâmicas da Ação}

À época da ação, uma das bibliotecárias desenvolvia pesquisa de doutorado sob orientação da docente responsável pela disciplina, o que constituiu um facilitador para o diálogo em torno da atuação conjunta. A partir do interesse da docente, se deu o planejamento das ações, com as bibliotecárias responsabilizando-se por criar mecanismos de gestão das atividades; apresentar a Wikipédia, seus princípios e lógicas constitutivas; dar suporte técnico às edições; oferecer atividades de capacitação para busca em

\footnotetext{
${ }^{4}$ Para mais informações sobre o GLAM Bibliotecas da USP:

https://pt.wikipedia.org/wiki/Wikipédia:GLAM/Bibliotecas_da_USP. Acesso em: 2 jul. 2021.
} 
fontes de informação qualificadas e responder dúvidas por e-mail ao longo do processo. À docente coube orientar e acompanhar os estudantes na escolha do tema e desenvolvimento dos textos, bem como avaliá-los.

Os estudantes definiram os verbetes a redigir, dentro do escopo da disciplina, cuja escolha foi previamente compartilhada e acordada com a docente e, posteriormente, comunicada às bibliotecárias. Além disso, foram sugeridos alguns verbetes, contudo, a escolha ficaria a cargo do estudante. Ficou estipulado que os estudantes poderiam decidir pela redação do verbete na Wikipédia como trabalho final da disciplina. Aqueles que preferissem poderiam elaborar o trabalho final em outra modalidade e não participar da atividade de edição na Wikipédia. Diante da participação opcional, do total de 53 estudantes, 25 optaram por participar da atividade e decidiram por trabalhar individualmente ou em grupos.

A informação em si (o verbete) não foi tomada como objetivo a ser alcançado; antes, estava em causa propor dinâmicas em que os estudantes experimentassem novas formas de relação com a informação, colocando-se como autores num circuito de amplo alcance, o que poderia contribuir como estratégia para problematizar o caráter de responsabilidade da comunicação pública, levando-os a construírem percepções sobre a importância da qualidade e confiabilidade dos conteúdos informacionais pesquisados e produzidos.

A partir disso, foi acordado que, com o acompanhamento da docente, as bibliotecárias conduziriam uma atividade para abordar aspectos da recepção, apropriação e produção de informações, incluindo questões em torno de princípios e lógicas que regem a Wikipédia. A oficina sobre como editar nesse dispositivo ocorreria fora do horário de aula, privilegiadamente no período da tarde para incluir estudantes do matutino e do noturno, e seria gravada em vídeo para disponibilização aos estudantes, posteriormente ${ }^{5}$. Na medida em que a elaboração de verbetes era opcional, o mesmo ocorreu com a participação na oficina.

\footnotetext{
${ }^{5}$ A oficina pode ser visualizada em: https://www.youtube.com/watch?v=5cip1rTElyA\&t=700s.
} Acesso em: 2 jul. 2021. 
Combinou-se, também, que na primeira atividade com participação das bibliotecárias, os estudantes seriam interrogados sobre possível interesse em participarem de uma outra atividade remota, fora do horário de aula, sobre pesquisa em fontes de informação. Face ao convite, não houve manifestação de interesse tanto entre estudantes do matutino como do noturno, razão pela qual a atividade, que poderia ser complementar ou preparatória, não foi realizada.

\subsection{RECEPÇÃO, APROPRIAÇÃo E USO dE INFORMAÇõES: ATIVIDADE INICIAL}

A primeira atividade, realizada em 31 de agosto de 2020, tratou da informação como representação, portanto isenta de neutralidade, configurando "trilhas" que direcionam e definem nossas relações com o meio e conosco (FOUCAULT, 1988). Com base nessa premissa, a atividade foi desenvolvida a partir dos seguintes elementos:

a) confiabilidade e impactos das informações sobre as sociedades: buscouse provocar os estudantes para que refletissem sobre a construção da confiabilidade da informação (tanto pelo produtor como pelos seus diferentes públicos) e seus impactos sobre a população de um modo geral. A discussão foi desenvolvida a partir de dois casos concretos, um inscrito na época em que o rádio era o principal veículo de comunicação, outro em 2020, no contexto da internet:

- a narração feita por Olson Welles, em 1938, da obra ficcional Guerra dos mundos, de H. G. Wells, em programa de rádio estadunidense, que levou parcela dos ouvintes a acreditar que os Estados Unidos da América estavam sendo invadidos por seres extraterrestres (SCHWARTZ, 2015);

- o caso da revista predatória Asian Journal of Medicine and Health que publicou, em julho de 2020, um estudo que promovia o uso da hidroxicloroquina no tratamento da Covid-19. O estudo, que já havia sido recusado por 
diversas revistas de prestígio, foi citado por jornalistas de diferentes regiões do mundo como um estudo científico tão válido quanto qualquer outro. Já conhecida como predatória no meio científico, alguns pesquisadores se mobilizaram para publicar na revista um artigo em que correlacionaram o uso da hidroxicloroquina e da azitromicina combinadas com a redução de acidentes de patinete em Marselha, França. A ação configurou um alerta para a falta de critérios de qualidade desta publicação, que havia sido amplamente citada pela imprensa (CAPUCHINHO, 2020).

b) a relação crítica com informações: foram abordados pontos acerca da importância da relação crítica com as informações, começando-se pela essencialidade de se considerar a fonte que está servindo de base à produção do trabalho, investigando sua história e objetivos. Aspectos como: pesquisar sobre o autor; verificar a data da informação, contextualizando-a no tempo e no espaço; não se limitar a um único conteúdo sobre um tema e buscar outras fontes que auxiliem à compreensão da questão; evitar assumir posição valorativa no momento da leitura, o que prejudica a construção da compreensão do texto; consultar informações provenientes de especialistas sobre o tema; e, solicitar auxílio aos bibliotecários para buscar informações. Esses tópicos foram salientados como condutas metodológicas que integram a perspectiva crítica considerada;

c) introdução à Wikipédia: além de discussões sobre alcance e abrangência da Wikipédia, a ferramenta foi abordada a partir dos princípios que the dão sustentação: trata-se de uma enciclopédia; regese pela imparcialidade; é de conteúdo livre; possui normas de conduta estabelecidas pela comunidade e para os seus colaboradores; não possui regras fixas. Nessa direção, um dos pontos abordados foi o caráter da escrita numa enciclopédia digital, com destaque à compreensão do texto enciclopédico, da escrita impessoal e descritiva 
que demanda a maior clareza possível ao público em geral (WIKI MOVIMENTO BRASIL, 2020).

\subsection{OfICINA SOBRE WIKIPÉdIA}

A oficina, realizada em 14 de outubro de 2020, contou com a participação de 25 estudantes e durou aproximadamente duas horas. Previamente à atividade, foi enviado e-mail aos estudantes com orientações para que realizassem o cadastro na Wikipédia. A metodologia para a produção dos verbetes, preparando os estudantes para a operacionalização da atividade, foi trabalhada a partir dos seguintes pontos:

Quadro 1 - Produção de verbetes na Wikipédia: aspectos abordados

\begin{tabular}{|c|l|}
\hline & $\begin{array}{l}\text { criar verbete ou editar algum existente: pesquisar previamente pelo } \\
\text { conteúdo, incluindo possíveis variações do termo; iniciar novos } \\
\text { verbetes na página de testes; } \\
\text { editor de texto e editor em código-fonte: o editor de texto é uma } \\
\text { opção para aqueles que não têm familiaridade com o código de } \\
\text { programação utilizado na Wikipédia; } \\
\text { página de testes do usuário: espaço destinado a testes e ao } \\
\text { desenvolvimento de textos fora da página principal da plataforma. Ou } \\
\text { seja, é um local ideal para que os iniciantes experimentem os recursos } \\
\text { da Wikipédia; } \\
\text { categorizar verbetes: as categorias atuam como descritores de } \\
\text { conteúdo, contribuindo para organizar os artigos criados. É um item } \\
\text { INSERÇÃO DE } \\
\text { Obrigatório; } \\
\text { traduzir verbetes da Wikipédia em outros idiomas para o } \\
\text { português: uso de ferramenta que possibilita pesquisar verbetes em } \\
\text { outros idiomas, verificar se existem na Wikipédia em português e } \\
\text { realizar tradução semiautomática, que demandará ajustes prévios à } \\
\text { publicação; } \\
\text { introduzir imagens: ilustrar os verbetes com imagens provenientes } \\
\text { do Wikimedia Commons - projeto Wikimedia que é repositório de } \\
\text { mídias para uso nos demais projetos, dentre eles a Wikipédia. }\end{array}$ \\
\hline
\end{tabular}




\begin{tabular}{|c|l|}
\hline PRODUÇÃO TEXTUAL & $\begin{array}{l}\text { referências: item obrigatório, todas as informações prescindem de } \\
\text { referências que devem ser vinculadas a cada parágrafo. Sua inserção } \\
\text { pode ser feita de modo manual - digitando os dados - ou automático } \\
\text { - pela extração de dados a partir do hiperlink do documento citado. No } \\
\text { final do verbete é gerada a lista de referências; } \\
\text { citações: a citação corresponde à indicação da fonte (referência) que } \\
\text { provê a informação fornecida no verbete, permitindo que o leitor saiba } \\
\text { a origem daquela informação; } \\
\text { livro de estilo: recomendações e regras que servem de referência à } \\
\text { elaboração dos verbetes na Wikipédia; visa assegurar consistência do } \\
\text { texto e sua formatação, orientando sobre padronizações que facilitam } \\
\text { tanto a leitura como a escrita colaborativa. }\end{array}$ \\
DIÁLOGOS ENTRE A & $\begin{array}{l}\text { página de discussão: artigos e páginas da Wikipédia possuem um } \\
\text { local destinado ao diálogo em torno dos conteúdos. Os editores } \\
\text { também possuem sua própria página de discussão, para trocas entre } \\
\text { si; } \\
\text { esplanada: espaço para troca de mensagens entre membros da } \\
\text { comunidade wikipedista que engloba votações, discussões de novas } \\
\text { regras, divulgação de eventos, entre outros elementos. }\end{array}$ \\
\hline EDITORES &
\end{tabular}

Fonte: Elaborado pelas autoras (2021)

Inicialmente, foram apresentados aspectos básicos de edição na Wikipédia e na sequência os estudantes realizaram edições em suas páginas de teste seguindo um roteiro estipulado previamente pelas bibliotecárias. Com isso, buscou-se garantir que todos explorassem elementos básicos de uso da ferramenta: criar seções, fazer destaques no texto, inserir referências e imagens, publicar um verbete.

A perspectiva foi possibilitar a construção de um domínio básico da ferramenta, a partir do qual os estudantes pudessem desenvolver a percepção de que já estariam aptos a operá-la, sendo então reforçado que a questão principal não seria somente manipular a Wikipédia, mas saber produzir um texto enciclopédico de boa qualidade, fazendo uso de fontes confiáveis devidamente referenciadas. Na sequência, os demais aspectos sobre a comunicação com a comunidade da Wikipédia foram elencados e abordados, sendo salientado que as bibliotecárias estariam à disposição para esclarecimento de dúvidas, posteriormente. 


\subsection{SeleÇão dos VerbeteS}

Os estudantes escolheram os verbetes que iriam editar e puderam optar pela criação de um novo item ou pela edição de verbetes já existentes. A partir dessa seleção, os estudantes discutiram com a docente sobre a pertinência do tema face aos conteúdos trabalhados ao longo do curso. Com isso, buscou-se conferir margem para a manifestação dos desejos de conhecer de cada um, fundamental às vinculações com o patrimônio simbólico e à mobilização na produção de conhecimentos (CHARLOT, 2008).

A docente não ocupou a posição de validar previamente os conteúdos produzidos pelos estudantes para serem publicados na Wikipédia, pois estava em causa que experimentassem a si mesmos como produtores de informação nessa enciclopédia digital sem a necessidade de que seus textos passassem por esfera de "validação" externa à Wikipédia. Assim, um verbete novo produzido ou um conteúdo criado num verbete já existente poderiam ser apagados pela comunidade wikipedista, caso não alcançassem critérios estipulados para sua manutenção. Nesse caso, caberia ao estudante entrar em dinâmicas de diálogo dentro da plataforma para reverter a exclusão do verbete se a considerasse indevida, ou mesmo melhorá-lo para que não fosse eliminado.

A ação resultou na criação dos verbetes: infoeducação, Estação Memória, biblioteca parque e decolonialidade, este último com mais de 2.526 visualizações no período de 29 de julho a 27 de agosto de 2021 (WIKIPÉDIA, 2021). Além desses, foram editados: mediação cultural, sala de leitura, podcasting, biblioteca acadêmica, sociedade da informação, análise cultural, biblioteca escolar, catálogo de acesso público online (OPAC). Os verbetes Rede Escolar de Bibliotecas Interativas de São Bernardo do Campo e Estação do Conhecimento foram publicados, mas acabaram sendo eliminados conforme dinâmicas da Wikipédia, o mesmo ocorrendo com as edições no verbete biblioteca. 


\subsection{FerRAmEnTAS AuXILIARES À GestÃo dAS ATIVIDADES}

As bibliotecárias utilizaram dois recursos para gerir a ação. Um deles foi a página da atividade ${ }^{6}$, criada na própria Wikipédia na qual constavam informações detalhadas sobre a atividade, links para guias e orientações sobre edição e lista de verbetes que seriam editados. Construída para prover informações de interesse aos estudantes, tanto sobre a atividade como sobre edições na Wikipédia, a página é também meio para registro da ação desenvolvida e foi vinculada à página do GLAM Bibliotecas da USP.

Outro recurso empregado foi 0 Outreachdashboard 7 , ferramenta Wikimedia que permite monitorar e contabilizar edições realizadas pelos participantes inscritos em dada atividade. Como recurso de gerenciamento interessa, sobremaneira, aos organizadores da ação, pois permite identificar facilmente o que os participantes estão editando, além de gerar dados quantitativos que podem ser extraídos da plataforma.

\section{RESULTADOS E DISCUSSÃO}

A atividade em foco objetivou incluir os estudantes em processos de produção e comunicação escrita com responsabilidade pública no contexto digital, por meio do emprego da Wikipédia. Assim, mais que o domínio de um aparato técnico, estava em causa a construção de um saber atitudinal fundamental.

A experiência trouxe indícios do potencial de uso da Wikipédia em práticas de produção textual pois, além de seu caráter aberto, colaborativo e de amplo alcance, é pautada em regras e procedimentos de avaliação que podem contribuir à prática da escrita como ato que implica articular e contextualizar informações, elaborar construções textuais próprias sem recorrer ao plágio,

\footnotetext{
6 Página da atividade na Wikipédia em português: https://pt.wikipedia.org/wiki/Wikipédia:Edit-athon/Atividades_em_português/Infoeducação_e_Wikipédia_(2020). Acesso em: 1 jul. 2021.

7 Dados da atividade no Outreachdashboard:

https://outreachdashboard.wmflabs.org/courses/Biblioteca_da_ECA-

USP_e_Biblioteca_do_IME-USP/Infoeducação_e_Wikipédia_-

_2020_(14_de_outubro_de_2020)?enroll=infoeducacao. Acesso em: 1 jul. 2021.
}

Inf. Inf., Londrina, v. 26, n. 4, p. 645 - 669, out./dez. 2021. 
embasar o conteúdo em referências consistentes e estabelecer uma estrutura textual coesa.

Quando publicados na Wikipédia, os conteúdos são avaliados e aspectos como o plágio e o uso excessivo de citações diretas são observados, o que contribui para discutir e construir junto aos estudantes percepções acerca da apropriação e produção de informações no contexto científicoacadêmico, pois conforme exposto por uma participante, "foi muito desafiador fazer [o verbete] de forma menos acadêmica. Não dá para pôr citação direta, temos que articular o texto. Isso foi um desafio, não poder dizer que tal acadêmico disse tal coisa."

Nessa direção, outra estudante, que redigiu verbete excluído após processo de avaliação, afirmou: "fiquei insegura com essa escrita que não é a escrita acadêmica [...]. Eu publiquei e eliminaram sob justificativa de violar direito autoral". Assim, argumenta: "fiquei frustrada e pensando se aquilo que faço nos meus trabalhos é violação de direito autoral". As falas revelam incompreensões sobre a própria noção de produção textual acadêmica, tomada como possibilidade de uso irrestrito do recurso da citação direta, de empregar palavras de um autor ao invés de construir um texto próprio, concatenando ideias e argumentos, produzindo novos sentidos.

A questão dialoga com estudo em que Becker (2015) expõe que, ao longo da graduação, muitos estudantes redigem suas monografias por meio de cópias de trechos de outros textos, deixando de praticar a escrita como um recurso para exposição de ideias e de argumentação no plano simbólico, por meio de suas próprias palavras. Nesse sentido, a experiência evidenciou ter potencial para que os estudantes reelaborem os sentidos da produção textual acadêmica, por meio de dinâmicas que convidam a experimentar a produção de informações como ação que não corresponde ao mero repassar dados, mas que implica questionar, agregar e concatenar ideias, constituindo ato de significação. 
Se de um lado sobressaiu a importância de ações nessa direção, de outro modo, evidencia-se uma lacuna na educação superior, a ser ocupada por dispositivo que contribua aos processos de relação do estudante com a ordem simbólica, o que inclui processos que vão da pesquisa à comunicação de informação e conhecimento.

A atividade expôs o potencial da biblioteca universitária como dispositivo educativo, voltado às relações entre estudante, informação e conhecimento, ressaltando a importância do desenvolvimento de ações que ultrapassem o foco em habilitar o sujeito ao domínio de um aparato tecnológico, inscrevendoa na formação superior como dispositivo central nas dinâmicas de produção de sentidos no contexto científico-acadêmico.

Em contraponto, o caráter acessório da biblioteca na formação do estudante universitário acabou sendo salientado, na medida em que a experiência configurou ação pontual desenvolvida a partir do interesse comum entre docente e bibliotecárias. Embora tenha se mostrado profícua, práticas nessa direção permanecem residuais, evidência da cisão entre as esferas da Informação e Educação no ensino superior.

Contudo, ao tratarmos da questão das relações informação e educação superior como problemática que não se restringe ao acesso à informação, mas também compreende o aprender a se informar e a informar, ao apropriar-se de informações e conhecimentos, é demandado que dispositivos como a biblioteca universitária ocupem-se de práticas em torno de saberes e atitudes essenciais à formação do estudante como um sujeito que se relaciona afirmativamente com o patrimônio simbólico, produzindo sentidos no contexto científicoacadêmico.

\section{CONSIDERAÇÕES FINAIS}

A experiência revelou o potencial de práticas articuladas entre biblioteca universitária e sala de aula como meio afirmativo de contribuição nos 
processos de relação entre estudantes, informação e conhecimento, por meio do emprego da Wikipédia em práticas educativas em torno da apropriação de saberes informacionais.

Cabe reforçar que não estão em causa iniciativas para formar sujeitos competentes em Wikipédia, mas a apropriação desta como recurso não somente ao desenvolvimento de ações em torno dos processos de pesquisa, leitura e escrita pautados no rigor, na criticidade e na criatividade, mas também como possibilidade de experiência de realização de ato autônomo e criativo de escrita.

A ação confirmou que diálogos entre sala de aula e biblioteca universitária, delimitados a partir da formação do estudante como um sujeito que se relaciona afirmativamente com o universo informacional, tomada como meta comum a ambas as esferas, são essenciais.

Ações nessa direção configuram contribuição da comunidade acadêmica à melhoria de conteúdos informacionais disponíveis online em acesso aberto, favorecendo a formação do estudante como profissional e cidadão que faz uso da palavra escrita com responsabilidade pública, compreendendo informação e conhecimento como bens simbólicos a serem partilhados e que concorrem ao desenvolvimento das sociedades em suas variadas esferas.

\section{REFERÊNCIAS}

ADACHI, A. A. C. T. Evasão de estudantes de cursos de graduação da USP ingressantes nos anos de 2002, 2003 e 2004. 2017. 294 f. Tese (Doutorado em Educação) - Faculdade de Educação, Universidade de São Paulo, São Paulo, 2017. Disponível em: https://teses.usp.br/teses/disponiveis/48/48134/tde-13092017-152310/ptbr.php. Acesso em: 14 maio 2021.

BECKER, $\mathrm{H}$. Truques da escrita: para começar e terminar teses, livros e artigos. Tradução de Denise Bottmann. Rio de Janeiro: Zahar, 2015.

BELLETATI, V. C. F. Dificuldades de alunos ingressantes na universidade pública: alguns indicadores para reflexões sobre a docência universitária. 2011. 237 f. Tese (Doutorado em Educação) - Faculdade de Educação, Universidade de São Paulo, São Paulo, 2011. Disponível em: 
https:/teses.usp.br/teses/disponiveis/48/48134/tde-04082011-115006/ptbr.php. Acesso em: 13 maio 2021.

BRESCIA, A. T.; CIRINO, S. D.; CONCEIÇÃO, L. G. B.; SANTOS, M. R. G. Wikipédia: um recurso de ensino e aprendizagem na universidade. Revista Docência do Ensino Superior, Belo Horizonte, v. 5, n. 2, p. 101-128, 2015. Disponível em: https://periodicos.ufmg.br/index.php/rdes/article/view/2032/1363. Acesso em: 13 maio 2021.

BRUNER, J. Acts of meaning: four lectures on mind and culture. Cambridge: Harvard University Press, 1990.

BURKE, P. Uma história social do conhecimento II: da Enciclopédia a Wikipédia. Tradução de Denise Bottmann. Rio de Janeiro: Zahar, 2012.

CAPUCHINHO, C. Pesquisadores publicam estudo falso sobre cloroquina e patinetes para denunciar revista científica. RFI, 17 ago. 2020. Disponível em: https://www.rfi.fr/br/frança/20200817-pesquisadores-publicam-falso-estudosobre-cloroquina-e-patinetes-para-denunciar-revista-cient\%C3\%ADfica. Acesso em: 2 jul. 2021.

CAUNE, J. La médiation culturelle: une construction du lien social. Les enjeux de l'information et de la communication, n. 1, 2000. Disponível em: https://lesenjeux.univ-grenoble-alpes.fr/2000/varia/04-la-mediation-culturelleune-construction-du-lien-social. Acesso em: 14 maio 2021.

CHARLOT, B. Da relação com o saber: elementos para uma teoria. Tradução de Bruno Magne. Porto Alegre: Artmed, 2008.

CHARTIER, R. A aventura do livro: do leitor ao navegador: conversações com Jean Lebrun. Tradução de Reginaldo C. C. de Moraes. São Paulo: UNESP: Imprensa Oficial, 1999.

COULON, A. A condição de estudante: a entrada na vida universitária. Tradução de Georgina G. dos Santos e Sônia Maria R. Sampaio. Salvador: EDUFBA, 2008.

FOUCAULT, M. Isto não é um cachimbo. Tradução de Jorge Coli. Rio de Janeiro: Paz e Terra, 1988. (Coleção Oficina das artes).

FREITAS, A. L. S. de. Curiosidade epistemológica. In: STRECK, D. R.; REDIN, E.; ZITKOSKI, J. J. (org.). Dicionário Paulo Freire. Belo Horizonte: Autêntica, 2008. p. 107-109.

LARROSA, J. Tremores: escritos sobre experiência. Tradução de Cristina Antunes, João Wanderley Geraldi. Belo Horizonte: Autêntica, 2015. (Educação: experiência e sentido). 
LOGAN, R. K. Que é informação?: a propagação da organização na biosfera, na simbolosfera, na tecnosfera e na econosfera. Tradução de Adriana Braga. Rio de Janeiro: Contraponto, 2012.

MATTELART, A. História da sociedade da informação. Tradução de Nicolás Nyimi Campanário. São Paulo: Loyola, 2002.

MESEGUER-ARTOLA, A.; RODRÍGUEZ-ARDURA, I.; AMMETLLER, G.; RIMBAU-GILABERT, E. Academic impact and perceived value of Wikipedia as a primary learning resource in higher education. Profesional de la información, León, v. 29, n. 3, p. 1-16, 2020. Disponível em: https://doi.org/10.3145/epi.2020.may.29. Acesso em: 17 ago. 2021.

PERROTTI, E. Olhando a significação: do paradigma do acesso ao da apropriação da informação. In: MARTELETO, R. M.; STOTZ, E. Informação, saúde e redes sociais: diálogos de conhecimentos nas comunidades da Maré. Rio de Janeiro: Fiocruz; Belo Horizonte: UFMG, 2009.

PERROTTI, E.; PIERUCCINI, I. Novos saberes para a educação do século XXI. In: MENDONÇA, R. H.; MARTINS, M. F. (org.). Salto para o futuro: tv, educação e formação de professores. v. 4, edição especial. Rio de Janeiro: Salto para o futuro/Tv escola/SEB-MEC, 2013. p. 9-25. Disponível em: http://www2.eca.usp.br/nucleos/colabori/documentos/vol_4_salto_para_o_futur o_20_anos.pdf. Acesso em: 14 maio 2021.

PIERUCCINI, I. A ordem informacional dialógica: estudo sobre a busca de informação em educação. 2004. 232 f. Tese (Doutorado em Ciência da Informação) - Escola de Comunicações e Artes, Universidade de São Paulo, São Paulo, 2004.

THOMAS, P. A.; JONES, M. F.; MATTINGLY, S. G. Using Wikipedia to teach scholarly peer review. Journal of Information Literacy, v. 15, n. 2, p. 178-190, 2021. Disponível em: https://ojs.lboro.ac.uk/JIL/article/view/PRJ-V1512-3. Acesso em: 17 ago. 2021.

SCHWARTZ, A. B. Broadcast hysteria: Orson Welles's War of the Worlds and the art of fake news. New York: Hill and Wang, 2015.

VANDERDORPE, C. Wikipedia and the ecosystem of knowledge. Scholarly and Research Communication, v. 6, n. 3, p. 1-10, 2015. Disponível em: https://doi.org/10.22230/src.2015v6n3a201. Acesso em: 14 maio 2021.

VIANA, L. Biblioteca universitária e formação científico-acadêmica: mediação cultural como modelo epistêmico. 2021. 219 f. Tese (Doutorado em Ciência da Informação) - Escola de Comunicações e Artes, Universidade de São Paulo, São Paulo, 2021. Disponível em: https://www.teses.usp.br/teses/disponiveis/27/27151/tde-26082021225536/publico/LilianVianaCorrigida.pdf. Acesso: 27 ago. 2021. 
WIKI MOVIMENTO BRASIL. Wikipédia de A a Z. São Paulo: Wiki Movimento Brasil, 2020. Disponível em:

https://upload.wikimedia.org/wikipedia/commons/a/a4/Wikipédia_de_A_a_Z.pdf. Acesso em: 14 maio 2021.

WIKIPÉDIA. Informações sobre "Decolonialidade". Disponível em: https://pt.wikipedia.org/w/index.php?title=Decolonialidade\&action=info\#. Acesso em: 28 ago. 2021.

\title{
UNIVERSITY LIBRARY AND THE PROCESS OF DEVELOPING NEW INFORMATIONAL KNOWLEDGE: AN EXPERIENCE WITH WIKIPEDIA
}

\begin{abstract}
Objective: Based on an experience conducted between the university library and the classroom, using the digital encyclopedia Wikipedia, the study approaches the university library as an educational dispositif, concerned with the exploitation of informational knowledge by students. Methodology: Qualitative, exploratory, and participant research. Results: The experience revealed the potential of using Wikipedia in textual production practices that could contribute to the development, with students, of perceptions about the exploitation and derivation of meaning of information in the scientific-academic culture. Moreover, the study showed the potential of the university library as an educational dispositif that is concerned with actions aimed at the dynamics involved in the derivation of meaning in the scientific-academic context. Conclusions: The study indicated the potential of dialogues between the university library and the classroom by means of the development of actions to achieve the education of the student in the ambit of information and knowledge as a common goal for both. It was considered that the development of the university library's educational dimension requires methodologies and practices of exploitation of informational knowledge. This aspect led to the highlighting of the potential of using Wikipedia in processes of research, reading, writing and, also, for students to experience writing as an autonomous and creative act.
\end{abstract}

Descriptors: University library. Higher education. Informational knowledge. Wikipedia.

\section{BIBLIOTECA UNIVERSITARIA Y SABERES INFORMATIVOS: UNA EXPERIENCIA CON WIKIPEDIA}

\section{RESUMEN}

Objetivo: A partir de una experiencia realizada de forma conjunta entre la biblioteca universitaria y el aula, utilizando la enciclopedia digital Wikipedia, el estudio aborda la biblioteca universitaria como dispositivo educativo, preocupado por la apropiación del conocimiento informativo por parte de los estudiantes. Metodología: Investigación cualitativa, exploratoria y participante. Resultados: La experiencia reveló indicios del 
potencial de uso de Wikipédia en las prácticas de producción textual que contribuyen a la construcción, junto a los estudiantes, de percepciones sobre la apropiación y la producción de información en la cultura científico-académica. Además, expuso la relevancia de la biblioteca universitaria como dispositivo educativo para ocuparse de las acciones dirigidas a las dinámicas de producción de sentido en el contexto científico-académico. Conclusiones: El estudio destaca la importancia de los diálogos entre la biblioteca universitaria y la sala de aula por medio del desarrollo de acciones que tienen como meta común, a ambas esferas, la formación del estudiante como sujeto que se relaciona afirmativamente con la información y el conocimiento. Se consideró que el desarrollo de la dimensión educativa de la biblioteca universitaria requiere de metodologías y prácticas concretas en torno a la apropiación del conocimiento informativo, aspecto que llevó a señalar el potencial del uso de Wikipedia en acciones relacionadas con los procesos de investigación, lectura, escritura y también para que los estudiantes experimenten la escritura como un acto autónomo y creativo.

Descriptores: Biblioteca universitaria. La educación superior. Conocimientos informativos. Wikipedia.

Recebido em: 28.08.2021

Aceito em: 09.12. 2021 